\title{
Archivos de Cardiología de México

\section{La proliferación de los miocitos ventriculares del corazón de mamífero adulto: un fenómeno esporádico pero factible}

\section{Alvaro Vargas-González*}

\author{
Departamento de Fisiología, Instituto Nacional de Cardiología Ignacio Chávez, México, D.F., México
}

Recibido el 25 de septiembre de 2012; aceptado el 6 de enero de 2014

\author{
PALABRAS CLAVE \\ Miocitos cardíacos \\ ventriculares; \\ Etapa adulta; \\ Síntesis de ADN; \\ Mitosis; \\ Citocinesis y \\ desdiferenciación; \\ Proliferación; \\ México
}

\section{KEYWORDS}

Ventricular

cardiomyocytes;

Adult stage;

DNA synthesis;

Mitosis;

Cytokinesis and dedifferentiation;

Proliferation;

Mexico

\begin{abstract}
Resumen La proliferación de los miocitos que forman parte de los ventrículos cardíacos del mamífero adulto ha sido descartada por algunos investigadores con el argumento de que estas células están diferenciadas en forma terminal; sin embargo, este dogma ha sido puesto en duda a partir de los hallazgos de otros investigadores quienes han observado que estos miocitos pueden presentar los procesos necesarios para la proliferación, es decir síntesis de ADN, mitosis y citocinesis, cuando el miocardio se daña en forma experimental con estrategias de tipo farmacológico o quirúrgico, o debido a condiciones patológicas relacionadas con el sistema cardiovascular. Esta revisión integra algunos de los trabajos disponibles en la literatura que han evaluado la síntesis del ADN, mitosis y citocinesis en estas células, en el miocardio dañado, para saber si su proliferación puede ser considerada como un fenómeno factible. La revisión concluye con una reflexión sobre las perspectivas del conocimiento generado en esta área de estudio.

(c) 2012 Instituto Nacional de Cardiología Ignacio Chávez. Publicado por Masson Doyma México S.A. Todos los derechos reservados.
\end{abstract}

Proliferation of adult mammalian ventricular cardiomyocytes: A sporadic but feasible phenomenon

\begin{abstract}
Proliferation of adult mammalian ventricular cardiomyocytes has been ruled out by some researchers, who have argued that these cells are terminally differentiated; however, this dogma has been rejected because other researchers have reported that these cells can present the processes necessary to proliferate, that is, DNA synthesis, mitosis and cytokinesis when the heart is damaged experimentally through pharmacological and surgical strategies or due to pathological conditions concerning the cardiovascular system. This review integrates some of the available works in the literature evaluating the DNA synthesis, mitosis and cytokinesis
\end{abstract}

\footnotetext{
* Juan Badiano n. ${ }^{\circ}$ 1, Colonia Sección XVI, Delegación Tlalpan, C.P. 14080. México D.F., México. Teléfono: +52 (55) 55732911 , ext 1278. Fax: $+52(55) 55730926$.

Correo electrónico: varalv@cardiologia.org.mx
} 
in these myocytes, when the myocardium is damaged, with the purpose of knowing if their proliferation can be considered as a feasible phenomenon. The review is concluded with a reflection about the perspectives of the knowledge generated in this area.

(c) 2012 Instituto Nacional de Cardiología Ignacio Chávez. Published by Masson Doyma México S.A. All rights reserved.

\section{Introducción}

La capacidad de proliferación in situ de los miocitos ventriculares del corazón de mamífero adulto ha sido abordada por los investigadores desde hace varias décadas. Algunos autores $^{1,2}$, desde el siglo pasado, descartaron este fenómeno con el argumento de que estas células se encuentran en un estado de diferenciación terminal que limita su división.

Sin embargo, el dogma según el cual los mocitos ventriculares del corazón de mamífero adulto carecen de capacidad proliferativa fue puesto en duda a partir de los trabajos de otros autores ${ }^{3-8}$ quienes encontraron que estas células pueden presentar los procesos necesarios para la proliferación, es decir síntesis de ADN, mitosis y citocinesis, cuando el miocardio es dañado.

Por esta razón, algunos investigadores suponen que los miocitos cardíacos ventriculares de mamífero adulto pueden proliferar, pero consideran que se carece de una evidencia clara de proliferación de este tipo celular ${ }^{9}$ porque el fenómeno ha sido subestimado debido a las dificultades técnicas para evaluarlo derivadas de su tasa de recambio baja en comparación con los otros tipos celulares del corazón ${ }^{10}$.

Además, existe una heterogeneidad en la forma en que los investigadores han hecho el conteo de los miocitos cardíacos que presentan estos procesos y en la manera de expresar los resultados obtenidos, lo que ha hecho difícil concluir si la proliferación de estas células es un fenómeno factible.

En esta revisión se integran los hallazgos de algunos de los trabajos disponibles en la literatura, que han abordado los procesos necesarios en la proliferación de los miocitos ventriculares cardíacos de mamífero adulto con daño del miocardio, inducido en forma experimental en modelos animales o asociado a condiciones patológicas en el humano, con el propósito de saber si esta proliferación es factible.

La integración de esos trabajos incluye la expresión de la cantidad de miocitos cardíacos con síntesis de ADN, en mitosis o citocinesis informada en cada caso, como el promedio de los valores encontrados en regiones diferentes; y la expresión de este promedio como el índice de marcaje en términos de la cantidad de miocitos cardíacos, que presentan el proceso, por cada 1,000,000 de miocitos cardíacos encontrados.

La integración de la información obtenida está hecha a la luz de los datos disponibles sobre estos procesos en los miocitos ventriculares del miocardio de mamífero adulto sin daño, y en el miocardio de mamífero en desarrollo cuando la actividad de estos procesos es máxima, esto como una referencia necesaria.

\section{Síntesis del ADN en los miocitos cardíacos en el miocardio adulto dañado}

La síntesis del ADN en los miocitos de los ventrículos cardíacos de mamífero adulto, con daño, ha sido abordada por varios investigadores con estrategias distintas. Algunos grupos de investigación ${ }^{3,5-7,11-14}$ han estudiado este proceso después del daño inducido en forma experimental, en animales de laboratorio, y el derivado de condiciones clínicas adversas en el humano.

Las estrategias aplicadas con ese propósito han incluido la cuantificación de la expresión del ARNm del antígeno nuclear de proliferación celular (ANPC) y la búsqueda del ANPC mismo el cual actúa como cofactor de la polimerasa de ADN y se expresa principalmente durante la fase de síntesis del ciclo celular.

El ANPC por esa característica es considerado como marcador de la fase de síntesis ${ }^{15}$, y esto ha sido aprovechado para evaluar la producción del ácido nucleico en forma indirecta en términos de la proporción de miocitos que presentan el ANPC. A continuación se describen algunos hallazgos obtenidos con esas estrategias experimentales (tabla 1).

Reiss et al. ${ }^{11}$ evaluaron la expresión del ARNm del ANPC en miocitos ventriculares de rata adulta de 2 meses de edad con infarto del miocardio e insuficiencia cardíaca inducidos por medio de constricción de la arteria coronaria. Los investigadores hicieron esta evaluación a través de la técnica de reacción en cadena de la polimerasa con transcriptasa inversa, 7 días después de la cirugía, e incluyeron miocardio de rata en condiciones equivalentes, pero sin daño, como control.

El grupo de Reiss et al. ${ }^{11}$ encontró un valor máximo de $0.93 \pm 0.15$ en el miocardio dañado, el cual fue 9 veces mayor que el valor de $0.09 \pm 0.02$ encontrado en el miocardio control, lo que demuestra que la producción del ARNm del ANPC aumenta en los miocitos cardíacos cuando el miocardio está dañado y por lo tanto sugiere que la síntesis del ADN se reactiva en los miocitos cardíacos en esta condición.

Sin embargo, el aumento en la expresión del ARNm encontrado por estos investigadores ${ }^{11}$ puede ocurrir sin un incremento en la síntesis de la proteína, como lo mostró en forma previa un grupo de investigadores encabezado por Marino $^{16}$ en el miocardio de rata adulta de 21 días de edad; de manera que es necesario evaluar la presencia del ANPC mismo.

El mismo grupo de Reiss ${ }^{11}$ buscó el ANPC en muestras de miocardio equivalentes a las usadas para evaluar la expresión del ARNm de esta proteína, por medio de 
Tabla 1 Índice de marcaje obtenido en la evaluación de la expresión del ANPC y la incorporación de BrdU

\begin{tabular}{lrr}
\hline Referencia & \multicolumn{2}{c}{ Índice de marcaje (Cantidad de células con marca/1,000,000) } \\
\cline { 2 - 3 } & Miocardio con daño & Miocardio control \\
\hline Expresión de ANPC & 12,500 & 0 \\
Reiss et al. ${ }^{11}$ & 490,000 & 0 \\
Quaini et al. ${ }^{13}$ & 310,000 & 700 \\
Beltrami et al. & 40,000 & \\
Liu et al. & & 2,300 \\
Incorporación de BrdU & 10,400 & 0 \\
Reiss et al. ${ }^{5}$ & 3,400 & 1,750 \\
Beltrami et al. & 9,300 & 2,100 \\
Kajstura et al. ${ }^{14}$ & 4,900 & \\
Ishido et al. & & \\
\hline
\end{tabular}

ANPC: antígeno nuclear de proliferación celular; BrdU: bromodesoxiuridina.

inmunohistoquímica con un anticuerpo monoclonal específico para el ANPC, y estimó el índice de marcaje.

Los investigadores ${ }^{11}$ hallaron un índice promedio, que fue máximo a los 7 días después del daño, equivalente a 12,500 de cada 1,000,000, pero no encontraron marca en el miocardio control. Este hallazgo muestra que la síntesis del ANPC sí aumenta en los miocitos ventriculares en asociación con el incremento en la expresión de su ARNm cuando el miocardio se daña, y que este aumento es significativo, lo que abre la posibilidad de una reactivación de la síntesis de ADN en estas condiciones.

Ahuja et al. ${ }^{6}$ evaluaron la expresión del ANPC, además de otras proteínas, en los miocitos ventriculares de ratón adulto con daño cardíaco inducido con isoproterenol, un fármaco que promueve la actividad del corazón e incluso daña al miocardio porque estimula a los receptores adrenérgicos tipo $\beta^{17}$ e induce un aumento de la concentración de $\mathrm{Ca}^{+2}$ intracelular libre ${ }^{18}$. Los investigadores hicieron esta evaluación por medio de la técnica de inmunoblot, y compararon el resultado con la expresión de la proteína en los miocitos ventriculares de ratón sin daño cardíaco.

El grupo de Ahuja ${ }^{6}$ encontró el ANPC solo en los miocitos del miocardio dañado, lo cual demuestra que la producción de ANPC sí aumenta en estas células en asociación a la lesión $y$, en consecuencia, puede ser que la actividad de síntesis del ADN sí se reactive en esa condición.

Aún más, Quaini et al. ${ }^{13}$ evaluaron la presencia del ANPC en miocitos de humano adulto con insuficiencia cardíaca congestiva en 3 condiciones diferentes: en individuos con un promedio de edad de 42 años con insuficiencia cardíaca asociada a miocardiopatía dilatada, en pacientes con un promedio de edad de 54 años afectados por insuficiencia cardíaca derivada de miocardiopatía isquémica, y en individuos con un promedio de edad de 46 años con insuficiencia cardíaca por afección valvular.

Estos investigadores ${ }^{13}$ tomaron muestras del miocardio dañado, en forma inmediata al explante del corazón previo a trasplante cardíaco, y las procesaron para la búsqueda del ANPC con técnica inmunohistoquímica; e hicieron una búsqueda subsecuente de actina sarcomérica $\alpha$ del músculo cardíaco, también con inmunohistoquímica con un anticuerpo específico ${ }^{19}$, para identificar las miofibrillas contráctiles, su organización y, por lo tanto, poder distinguir los miocitos cardíacos de otros tipos celulares ${ }^{15}$. Los autores estimaron el índice de marcaje para el ANPC en las células marcadas para actina sarcomérica $\alpha$, y lo compararon con el índice obtenido en muestras de miocardio de individuos con un promedio de edad de 35 años y sin daño cardíaco, que murieron por trauma craneal o hemorragia cerebral, incluidas como control.

Quaini et al. ${ }^{13}$ encontraron un índice promedio equivalente a 490,000 de cada 1,000,000, en el miocardio con daño, que contrasta de forma evidente con una ausencia de miocitos con marca en el miocardio sin lesión. Este hallazgo coincide con lo observado en el miocardio de rata ${ }^{11}$ y refuerza la posibilidad de un aumento en la síntesis de ADN en condición de daño.

En otro estudio, Beltrami et al. ${ }^{5}$ evaluaron la presencia del ANPC en miocitos obtenidos del costado derecho del septo interventricular de corazón de humano después del trasplante de este en el adulto con un promedio de edad de 51 años, sometido a esta intervención por padecer insuficiencia cardíaca. Los autores del estudio evaluaron la presencia del ANPC como respuesta del corazón trasplantado al rechazo por parte del organismo receptor.

Estos investigadores ${ }^{5}$ tomaron biopsias del corazón trasplantado, entre 1 y 768 días después de la cirugía, y evaluaron la presencia del ANPC en los miocitos, así como la actina sarcomérica $\alpha$ del músculo cardíaco, con inmunohistoquímica; y estimaron el índice de marcaje. Los autores incluyeron muestras de corazón de individuos donadores con un promedio de 48 años de edad, y sin afección cardíaca, como control.

El grupo de Beltrami ${ }^{5}$ informó un índice promedio equivalente a 310,000 por cada 1,000,000 en el miocardio dañado y la ausencia de marca en el músculo usado como control en su estudio, hallazgo que concuerda con lo observado por Quaini et al. ${ }^{13} \mathrm{y}$, por lo tanto, fortalece la propuesta de que la síntesis de ADN en los miocitos cardíacos se reactiva en caso de daño.

Un grupo más, el encabezado por $\mathrm{Liu}^{7}$, evaluó la presencia del ANPC en miocitos ventriculares de perro criollo adulto, cuya edad fue omitida por los autores en su informe. El grupo de investigadores indujo insuficiencia cardíaca en 
los animales mediante constricción de la arteria coronaria, durante 4 semanas, evaluó la presencia de la proteína por medio de inmunohistoquímica, y estimó el índice respectivo; e incluyó miocardio de animales sometidos al mismo procedimiento quirúrgico, excepto el ligamiento, como control.

Los autores ${ }^{7}$ informaron un índice de marcaje promedio equivalente a 40,000 de cada 1,000,000 en el miocardio con daño y un índice equivalente a 700 por cada 1,000,000 en el miocardio sin lesión. El valor encontrado en el miocardio experimental fue un 5,614\% mayor que el encontrado en el miocardio control incluido en el estudio, y contrasta con la ausencia de marca para ANPC en el miocardio íntegro de rata $^{11}$ y de humano ${ }^{5,13}$, por lo que el hallazgo de Liu et al. ${ }^{7}$ apoya la propuesta ya hecha de un aumento significativo en la actividad de síntesis del ADN.

En resumen, los datos obtenidos en la cuantificación del ARNm y la búsqueda del ANPC sugieren que la síntesis del $A D N$ se reactiva con una magnitud significativa en los miocitos cardíacos del miocardio de mamífero adulto en asociación al daño $0^{5,7,11,13}$. Sin embargo es importante hacer notar, solo como un punto de referencia, que la expresión del ANPC en el miocardio adulto dañado es significativamente menor que su expresión en el miocardio prenatal en el cual la síntesis de $A D N$ es máxima debido al proceso dinámico de la organogénesis.

En este sentido, Ahuja et al. ${ }^{6}$ informaron que la expresión del ANPC en los miocitos cardíacos de ratón adulto dañado es menor que su expresión en el miocardio de ratón embrionario de 14 días de desarrollo evaluada por estos mismos autores con la misma técnica y con fines comparativos; y otros investigadores encontraron que los índices de marcaje en el miocardio lesionado de rata ${ }^{11}$, perro ${ }^{7}$ y humano ${ }^{5}$ adultos representan un 4,12 y $92 \%$, respectivamente, en comparación con el índice de marcaje equivalente a 335,100 de cada 1,000,000 encontrado por Quaini et al. ${ }^{13}$ en el miocardio fetal de humano de 22 semanas de edad, obtenido 5 a $10 \mathrm{~h}$ después del aborto, que estos autores incluyeron como control en la búsqueda de ANPC en el miocardio de humano lesionado.

Una excepción a lo anterior es el hecho de que el índice de marcaje en el miocardio adulto con lesión informado por Quaini et al. ${ }^{13}$ es mayor, en un $46 \%$, que el valor encontrado en el miocardio fetal por estos mismos investigadores a pesar de que las muestras de ambas condiciones fueron procesadas en forma semejante. Esto puede deberse a que la técnica inmunohistoquímica para el ANPC tiene una inespecificidad alta porque la proteína se produce en asociación con procesos distintos a la síntesis del ADN, por ejemplo la reparación de este ${ }^{15}$, por lo que la técnica suele arrojar índices de marcaje altos.

Lo anterior significa que el índice de marcaje en el miocardio lesionado puede ser mayor debido a procesos de reparación asociados al daño del ADN; sin embargo, esta propuesta no puede ser corroborada debido a que los otros estudios en los que se ha evaluado la presencia del ANPC no incluyeron miocardio prenatal como control.

En virtud de que la producción del ANPC en asociación con procesos diferentes a la síntesis del ADN impide asumir la presencia de esta proteína como un indicador de la producción de $A D N$, la evaluación de la síntesis de este ácido nucleico en los miocitos cardíacos ventriculares del corazón adulto dañado requiere la aplicación de técnicas que permitan su evaluación directa. Una de estas técnicas es la incorporación de análogos estructurales de las bases necesarias en la síntesis del ADN, por ejemplo la bromodesoxiuridina (BrdU), y la estimación del índice de marcaje en términos de la proporción de miocitos cuyos núcleos la retienen.

La BrdU es un análogo estructural de timidina que se incorpora al ADN durante su síntesis y puede ser detectada por medio de inmunohistoquímica con el uso de anticuerpos específicos ${ }^{15}$, por lo que su incorporación es considerada como un indicador directo de la síntesis del ácido nucleico. A continuación se describen algunos hallazgos obtenidos con esta estrategia.

El grupo de investigadores encabezado por Reiss ${ }^{11}$ evaluó la incorporación de la BrdU en muestras del miocardio en el cual evaluó la expresión del ARNm del ANPC y la presencia de esta proteína. Los investigadores tiñeron los núcleos celulares con bis-benzimida, un colorante fluorescente que se une en forma específica al ADN y permite su identificación, y así estimaron el índice de marcaje correspondiente.

El grupo de Reiss ${ }^{11}$ encontró un índice máximo equivalente a 10,400 de cada 1,000,000 en el miocardio dañado, 7 días después de la cirugía, que es un 352\% mayor que un índice promedio equivalente a 2,300 de cada 1,000,000 encontrado en el tejido sin lesión. Este hallazgo muestra que, en efecto, la síntesis del ADN se reactiva, y ocurre con una magnitud significativa, en los miocitos que se mantienen viables después del daño en el miocardio adulto.

Por otra parte, el grupo de Beltrami ${ }^{5}$ evaluó la incorporación de la BrdU en el miocardio con daño, como complemento a la búsqueda del ANPC hecha en su estudio. Los investigadores incubaron el tejido en solución de BrdU, hicieron una búsqueda de esta con inmunohistoquímica, tiñeron el tejido con un anticuerpo específico para actina sarcomérica $\alpha$ y contaron los miocitos que retuvieron la marca para estimar el índice de marcaje.

Ese grupo de trabajo ${ }^{5}$ encontró un índice promedio equivalente a 3,400 por cada 1,000,000 en el miocardio con daño, el cual contrasta con la ausencia de marca en el tejido sin lesión incluido en el estudio, y es un 48\% mayor que el índice de marcaje para la BrdU encontrado en el miocardio control de rata sin lesión ${ }^{11}$, lo que muestra una vez más que el proceso de síntesis de ADN se reactiva como respuesta al daño y que esto ocurre con una magnitud significativa.

En esta misma línea de abordaje experimental, el grupo de investigadores encabezado por Kajstura ${ }^{14}$ evaluó la incorporación de BrdU en los miocitos ventriculares de rata adulta de 2 meses de edad con daño cardíaco. Los investigadores indujeron insuficiencia cardíaca mediante estenosis crónica de la arteria coronaria, durante un periodo máximo de 3 meses, y evaluaron la incorporación de BrdU en los miocitos cardíacos a través de inmunohistoquímica y la tinción de núcleos con bis-benzimida. Los autores incluyeron miocardio de rata con características equivalentes pero sin daño como control.

Los investigadores ${ }^{14}$ encontraron un índice de marcaje equivalente a 9,300 de cada 1,000,000 en el miocardio con daño y un índice equivalente a 1,750 de cada 1,000,000 en el miocardio sin lesión. El índice encontrado en el miocardio dañado es un $431 \%$ mayor que el valor encontrado 
en el miocardio incluido como control, este es un 304\% mayor que el índice de marcaje para la BrdU informado para el miocardio de rata sin daño ${ }^{11}$ y contrasta con la ausencia de marca en el miocardio de humano sin lesión ${ }^{5}$, lo que constituye una evidencia más de que el proceso de síntesis del ADN se reactiva como respuesta al daño y que esto ocurre con una magnitud significativa.

Por último, Ishido et al. ${ }^{3}$ evaluaron la incorporación de la BrdU en miocitos ventriculares de ratón adulto de 3 semanas de edad, 3 días después de inducir un aumento de la actividad cardíaca in vivo a través de una administración única de isoproterenol. Los autores hicieron esta evaluación con inmunohistoquímica para la BrdU y tinción de las muestras del tejido con la técnica de hematoxilina y eosina para identificar la estructura celular; e incluyeron miocardio de ratón en condiciones semejantes de 2 semanas de edad, pero sin daño, como control.

Los autores ${ }^{3}$ encontraron un índice máximo equivalente a 4,900 de cada 1,000,000 en el miocardio dañado, y un índice promedio equivalente a 2,100 de cada 1,000,000 en el miocardio control. El valor encontrado en el miocardio experimental sobrepasa un 133\% el valor encontrado en el miocardio de ratón sin lesión incluido en este estudio y un $113 \%$ el índice de marcaje informado para el miocardio de rata sin daño ${ }^{11}$, y contrasta con la ausencia de miocitos marcados en el miocardio de humano sin daño ${ }^{5}$, por lo que el hallazgo se suma a las evidencias ya mostradas de un aumento significativo en la síntesis de ADN asociada al daño del miocardio.

En resumen, los datos obtenidos con la incorporación de la BrdU confirman la propuesta de que la síntesis del ADN en los miocitos cardíacos de mamífero adulto se reactiva en asociación con el daño, con una magnitud significativamente alta, propuesta derivada de los datos obtenidos de la cuantificación del ARNm del ANCP y la búsqueda del ANPC mismo.

Si los valores obtenidos en el miocardio con daño, mediante la incorporación de la BrdU, en general son significativamente menores que los obtenidos en la búsqueda del ANPC (como puede ser observado en la tabla 1), esto puede deberse a la mayor especificidad de la técnica para la BrdU en comparación con la técnica de búsqueda del ANPC $^{15}$ en cuanto a la detección de células que se encuentran en la fase de síntesis de ADN; y por lo tanto, esta diferencia no les resta relevancia a los hallazgos descritos. Sin embargo, es necesario mencionar que los índices de marcaje para la BrdU encontrados en el miocardio adulto con daño también distan de lo hallado en el miocardio en desarrollo.

En este sentido, los índices de marcaje para la BrdU encontrados en el miocardio lesionado de rata $^{14}$ y ratón ${ }^{3}$ adultos representan apenas el 3 y el $2 \%$, respectivamente, en comparación con el índice equivalente a 229,500 por cada 1,000,00 encontrado por Walsh et al. ${ }^{12}$ en el miocardio de ratón embrionario de 14.5 días de desarrollo con la misma estrategia. Esta diferencia sugiere que si la síntesis de ADN aumenta en forma significativa en el miocardio adulto dañado, esta es significativamente menor en comparación con su magnitud en el miocardio prenatal.

Los datos obtenidos en la cuantificación del ARNm del ANPC, la búsqueda del ANPC y la incorporación de la BrdU, en los miocitos ventriculares del corazón de mamífero adulto con daño, confirman que la síntesis del ADN se reactiva con una magnitud significativamente alta en el miocardio en esta condición, lo que pone en evidencia que la proliferación de los miocitos cardíacos es un fenómeno factible. Sin embargo, la síntesis de ADN en estos miocitos no necesariamente es seguida por su división mitótica ${ }^{11,14}$, de manera que es necesario revisar la incidencia de la cariocinesis en estas células y compararla con lo que sucede en el miocardio en desarrollo.

\section{Mitosis en los miocitos cardíacos del miocardio adulto dañado}

En relación con la mitosis en los miocitos ventriculares del corazón de mamífero adulto, en condición de daño, el grupo de Reiss ${ }^{11}$ exploró la ocurrencia de división mitótica en el miocardio de rata adulta con insuficiencia cardíaca congestiva, inducida con la estrategia quirúrgica ya descrita, y en el tejido control. El grupo de investigadores buscó miocitos con figuras mitóticas en general y metafases en particular, en el día 7 después de la cirugía, por medio de la administración de colchicina $(100 \mathrm{mg} / \mathrm{kg})$ por vía intravenosa, $3 \mathrm{~h}$ antes del sacrificio, para detener aquellos miocitos que se encontraban en esta fase; y tiñó el tejido con bis-benzimida para identificar los núcleos en su totalidad.

Reiss ${ }^{11}$ y su grupo encontraron metafases en varios miocitos en el tejido dañado pero no hallaron figuras mitóticas de ningún tipo en el tejido control, por lo que asumieron que la división mitótica se reactiva en este tipo celular en asociación con el daño del músculo cardíaco; sin embargo, los autores omitieron el conteo de las metafases y dejaron implícito que su ocurrencia es esporádica, de manera que la incidencia de mitosis en este tipo celular parece poco significativa en contraste con lo descrito para la síntesis de ADN. Sin embargo, la mitosis puede ocurrir.

El grupo de Quaini ${ }^{13}$ también exploró la actividad mitótica en los miocitos de humano con insuficiencia cardíaca congestiva en los que evaluó la presencia del ANPC, los cuales identificó a través de la tinción del miocardio con hematoxilina y eosina, y contó las células de este tipo con figuras mitóticas. Los autores incluyeron en el conteo solo aquellas figuras mitóticas ubicadas en células que tenían las miofibrillas, y las estriaciones características de la célula muscular cardíaca, para garantizar que el valor obtenido correspondía a miocitos cardíacos, y expresaron el valor en términos de la proporción de estos. Los investigadores compararon esta actividad con su contraparte en el miocardio de humano incluido como control en su estudio.

El grupo de trabajo ${ }^{13}$ encontró un índice mitótico máximo equivalente a 11 por cada $1,000,000$, en el miocardio con daño, pero no halló figuras mitóticas en el miocardio sin lesión, lo cual concuerda con la ausencia de estas observada en el tejido control de rata ${ }^{11}$. Este contraste es una evidencia más de que la mitosis puede reactivarse en los miocitos en condición de daño, aunque esta ocurre con una incidencia poco significativa si se compara con la síntesis de ADN.

Aún más, Beltrami et al. ${ }^{5}$ evaluaron la incidencia de división mitótica en los miocitos del septo interventricular del corazón trasplantado en el humano adulto, en el cual buscaron al ANPC, y su control respectivo.

En este estudio ${ }^{5}$ los investigadores encontraron solamente 3 figuras mitóticas en miocitos del tejido dañado, 
y ninguna en el miocardio sin lesión. La diferencia entre las 2 condiciones es clara y coincide con el contraste entre el miocardio con daño y el tejido íntegro informado por los otros autores ${ }^{11,13}$, a pesar de que el grupo de Beltrami ${ }^{5}$ omitió la expresión del valor como proporción; de manera que este es otro indicio de que la mitosis es más limitada que la síntesis de ADN pero puede reactivarse en asociación con el daño.

Por último, Liu et al. ${ }^{7}$ evaluaron la incidencia del proceso de mitosis en miocitos ventriculares de perro criollo, adulto, con insuficiencia cardíaca inducida con la estrategia quirúrgica ya mencionada. En este caso, los investigadores identificaron los núcleos de las células en su totalidad con una tinción del miocardio con bis-benzimida, e identificaron los miocitos cardíacos a través de la búsqueda de la actina sarcomérica $\alpha$ con inmunohistoquímica. Los investigadores compararon el valor encontrado con aquel en el control respectivo.

Estos autores ${ }^{7}$ encontraron un índice mitótico equivalente a 22 de cada 1,000,000, en el miocardio dañado, que contrasta con una ausencia de miocitos en mitosis en el tejido control incluido en el estudio y con su ausencia en el miocardio de rata ${ }^{11}$ y de humano ${ }^{5,13}$ adultos sin daño. En este caso la diferencia entre el miocardio dañado y el miocardio sin lesión también es notoria, por lo que se suma a las evidencias de que la mitosis es un fenómeno factible a pesar de que también se suma a las evidencias de que su incidencia es mínima en contraste con la síntesis del ADN.

En resumen, los datos publicados que conciernen a la mitosis en los miocitos cardíacos ventriculares del corazón de mamífero adulto con daño muestran que su incidencia es mínima en comparación con la incidencia de la síntesis de ADN y en forma independiente del modelo experimental usado o la condición patológica en que se evalúa, lo que significa que la mitosis no siempre sigue a la síntesis del ADN; aunque también muestran que la proliferación de estos miocitos es un fenómeno factible.

Sin embargo, es importante mencionar que la incidencia de la mitosis en caso de daño es significativamente menor que su incidencia en el miocardio en desarrollo, en particular si se compara con un índice mitótico equivalente a 180 de cada 1,000,000 encontrado por Quaini et al. ${ }^{13}$ en el miocardio fetal de humano, de 22 semanas de edad, usado como control.

Es importante recordar que el proceso de mitosis finaliza cuando las 2 células formadas de novo se separan por medio del proceso conocido como citocinesis por lo que a continuación, y por último, se revisa la incidencia de la citocinesis en los miocitos ventriculares del corazón de mamífero adulto con daño como un proceso necesario en la formación de miocitos nuevos a través de mitosis en el organismo adulto.

\section{Citocinesis en los miocitos cardíacos del miocardio adulto dañado}

Ya se mencionó que algunos investigadores ${ }^{1,2}$ han argumentado que los miocitos cardíacos de mamífero adulto carecen de capacidad de división porque se encuentran en un estado de diferenciación terminal que la limita. Por esta razón, la citocinesis en estos miocitos ha sido estudiada a la par con su estado de diferenciación.
La citocinesis ha sido evaluada a través de la búsqueda de un anillo contráctil en la parte media del citoplasma, que se forma antes de la división celular ${ }^{20,21}$, por medio de microscopía de campo claro; y el estado de diferenciación ha sido evaluado mediante la búsqueda de las proteínas que forman las miofibrillas del aparato contráctil, la actina sarcomérica $\alpha$ en particular, a través de inmunohistoquímica: la organización de las proteínas en miofibrillas y el arreglo de las miofibrillas en paquetes son característicos del estado diferenciado, y la pérdida de esta estructura es considerada como un rasgo de desdiferenciación. A continuación se describen algunos hallazgos al respecto.

Ya se mencionó en este trabajo que Quaini et al. ${ }^{13}$ identificaron los miocitos cardíacos basándose en la presencia de las miofibrillas y estriaciones características de este tipo celular. Sin embargo los autores encontraron células en división que fueron calificadas como miocitos cardíacos por su localización y apariencia, pero que carecían de miofibrillas, por lo que concluyeron que se trataba de miocitos cardíacos desdiferenciados.

Por otra parte, Kajstura et al. ${ }^{4}$ revisaron la organización de las miofibrillas contráctiles en los miocitos cardíacos de humano adulto con enfermedad cardíaca isquémica, y en los miocitos cardíacos de humano sin lesión, en los cuales evaluaron la actividad mitótica a través de la búsqueda de actina sarcomérica $\alpha$ con inmunohistoquímica. Este grupo encontró miocitos en mitosis con sus miofibrillas contráctiles desorganizadas, por lo que concluyó que se trataba de miocitos cardíacos en proceso de desdiferenciación. Esta observación concuerda con la informada por los otros autores ${ }^{13}$ y ambos hallazgos coinciden con un fenómeno descrito en los miocitos cardíacos embrionarios ${ }^{22}$.

Ahuja et al. ${ }^{22}$ observaron que en los miocitos cardíacos de rata en el día 14 del desarrollo embrionario las miofibrillas contráctiles entran en un proceso de desorganización en la prometafase que se mantiene durante la citocinesis: las miofibrillas se desensamblan antes del inicio de la citocinesis y se reensamblan cuando esta culmina; por lo que este fenómeno ha sido interpretado como un proceso de desdiferenciación transitoria necesario en la citocinesis. Este hallazgo permite suponer que lo descrito en el miocardio adulto dañado ${ }^{4,13}$ es parte de un proceso de desdiferenciación de los miocitos cardíacos asociado al daño, es decir una reversión del estado diferenciado en la etapa adulta que posibilita su citocinesis.

Aún más, ahora existe evidencia de que el aparato contráctil de los miocitos cardíacos en el mamífero adulto es un sistema dinámico que se encuentra en un proceso continuo de ensamble y desensamble de las miofibrillas ${ }^{23}$, que recuerda al proceso descrito en el miocardio embrionario ${ }^{22}$, lo que sugiere que los miocitos cardíacos adultos pueden entrar en citocinesis.

Por otra parte, Ahuja et al. ${ }^{6}$ evaluaron la expresión de la proteína RhoA y sus proteínas efectoras Cdc42, Rac1, ROCK । y ROCK I| en los mismos miocitos ventriculares de ratón adulto después del daño cardíaco con isoproterenol, y en miocitos sin lesión, en los que evaluaron la expresión del ANPC por medio de inmunoblot. Los investigadores se interesaron en estas proteínas porque se sabe que estas actúan como reguladores en la formación del anillo contráctil necesario en la citocinesis ${ }^{24}$. Los autores encontraron que RhoA, Cdc42, Rac1, ROCK । y ROCK II se expresan en el 
miocardio dañado pero su expresión es prácticamente nula en el tejido sin lesión, lo que indica que al menos esta parte del sistema bioquímico promotor de la citocinesis se reactiva en los miocitos cardíacos de mamífero adulto cuando el miocardio se daña y puede contribuir a la citocinesis. Sin embargo, es necesario destacar, como un punto de referencia, que la expresión de estas proteínas en el miocardio adulto dañado es menor que su expresión en el miocardio prenatal como mostraron los mismos autores ${ }^{6}$.

Ahuja et al. ${ }^{6}$ evaluaron la expresión de RhoA, Cdc42, Rac1, ROCK । y ROCK ॥ en el miocardio de ratón embrionario de 14 días de desarrollo para comparar lo observado en el adulto. Los investigadores encontraron que la expresión de estas proteínas en la etapa adulta, en general, es menor que en la etapa embrionaria lo que sugiere a la vez que la capacidad de formación del anillo contráctili ${ }^{24}$ y la capacidad de citocinesis también es menor, y esto puede explicar la incidencia limitada de citocinesis en los miocitos cardíacos adultos ${ }^{4,6}$.

Kajstura et al. ${ }^{4}$ encontraron solamente un miocito en citocinesis, en el miocardio afectado por miocardiopatía dilatada; mientras que Ahuja et al. ${ }^{6}$ hallaron una proporción de miocitos cardíacos binucleados, derivados de un proceso de división incompleto en el miocardio ventricular de ratón adulto dañado con isoproterenol, que equivale a más del triple (40\%) en comparación con la encontrada en el tejido control (13\%). Ambos datos confirman que la división completa del citoplasma de los miocitos cardíacos adultos ocurre en forma limitada a pesar de su capacidad de desdiferenciación, lo que puede explicar la carencia de una evidencia clara de proliferación de los miocitos cardíacos en condición de daño que ya fue comentada ${ }^{4,9}$.

Los datos sobre la citocinesis y la desdiferenciación en los miocitos cardíacos ventriculares del corazón de mamífero adulto con daño muestran que su incidencia es limitada, más que la mitosis y aún más que la síntesis de $A D N$, de manera que la proliferación de estas células depende de los mecanismos promotores de la síntesis del ADN pero sobre todo de aquellos mecanismos que controlan la mitosis ${ }^{25}$, la citocinesis $^{23}$ y la desdiferenciación. Sin embargo, si la citocinesis y la desdiferenciación pueden ocurrir, estos procesos hacen posible la proliferación de este tipo celular.

El potencial de proliferación de los miocitos ventriculares del corazón de mamífero adulto, mostrado en este trabajo, genera expectativas en el área clínica. Si se logra conocer la forma de aumentar la incidencia de su proliferación de manera significativa se abrirá la posibilidad de estimularla para tratar el daño del miocardio en el humano, derivado de condiciones patológicas, y mitigar sus consecuencias adversas.

La estimulación de la proliferación de los miocitos cardíacos ventriculares diferenciados in situ en el mamífero adulto podrá contribuir junto con otras vías, tal como la proliferación y diferenciación de células troncales ${ }^{26-28}$, a la formación de miocitos cardíacos de novo que puedan ayudar a la reparación «endógena» del corazón dañado; por lo que el estudio de los factores fisiológicos y moleculares que regulan la síntesis del $A D N$ y, sobre todo, la mitosis, la citocinesis y la desdiferenciación en este tipo celular está justificado plenamente.

\section{Conclusiones}

Los datos revisados muestran que la síntesis del ADN y la mitosis en los miocitos que forman los ventrículos cardíacos de mamífero adulto se reactivan y que su incidencia aumenta en forma significativa cuando el miocardio se daña, a pesar de que esta es menor que en la etapa prenatal; y con relación a la citocinesis, ocurre una reactivación de al menos una parte de los mecanismos que la regulan a pesar de que su actividad también puede ser menor que aquella en la etapa prenatal y de que la división celular ocurre en forma más limitada que los otros procesos. Por lo tanto, la proliferación de los miocitos cardíacos puede ser considerada como un fenómeno esporádico pero factible, por lo que conviene continuar con el estudio de los factores reguladores de la síntesis del ADN y, sobre todo, de la mitosis y la citocinesis en este tipo celular.

\section{Financiación}

No se recibió patrocinio de ningún tipo para la escritura de este artículo.

\section{Conflicto de intereses}

El autor declara no tener ningún conflicto de intereses.

\section{Agradecimientos}

El autor agradece a Jesús Manuel León Cázares y Elizabeth Flores Rodríguez, así como a los revisores anónimos, sus comentarios valiosos a este manuscrito.

\section{Bibliografía}

1. Rumyantsev PP. Interrelations of the proliferation and differentiation processes during cardiac myogenesis and regeneration. Int Rev Cytol. 1977; 51:186-273.

2. McGill CJ, Brooks G. Cell cycle control mechanisms and their role in cardiac growth. Cardiovasc Res. 1995;30:557-69.

3. Ishido S, Yokoyama M, Kitazawa S, et al. DNA resynthesis and binucleated metamorphosis in cardiac muscle cells after isoproterenol-induced injury: bromodeoxyuridine immunohistochemistry. Am J Cardiovasc Pathol. 1994;5:49-54.

4. Kajstura J, Leri A, Finato N, et al. Myocyte proliferation in end-stage cardiac failure in humans. Proc Natl Acad Sci U S A. 1998;95:8801-5.

5. Beltrami CA, Di Loreto C, Finato N, et al. Proliferating cell nuclear antigen (PCNA), DNA synthesis and mitosis in myocytes following cardiac transplantation in man. J Mol Cell Cardiol. 1997;29:2789-802.

6. Ahuja P, Perriard E, Pedrazzini T, et al. Re-expression of proteins involved in cytokinesis during cardiac hypertrophy. Exp Cell Res. 2007;313:1270-83.

7. Liu Y, Cigola E, Cheng W, et al. Myocyte nuclear mitotic division and programmed myocyte cell death characterize the cardiac myopathy induced by rapid ventricular pacing in dogs. Lab Invest. 1995;73:771-87.

8. Beltrami AP, Urbanek K, Kajstura J, et al. Evidence that human cardiac myocytes divide after myocardial infarction. N Engl J Med. 2001;344:1750-7. 
9. Engel FB. Cardiomyocyte proliferation: A platform for mammalian cardiac repair. Cell Cycle. 2005;4:1360-3.

10. Senyo SE, Steinhauser ML, Pizzimenti CL, et al. Mammalian heart renewal by pre-existing cardiomyocytes. Nature. 2013;493:433-7.

11. Reiss K, Kajstura J, Zhang X, et al. Acute myocardial infarction leads to upregulation of the IGF-1 autocrine system, DNA replication, and nuclear mitotic division in the remaining viable cardiac myoctes. Exp Cell Res. 1994;213:463-72.

12. Walsh S, Pontén A, Fleischmann BK, et al. Cardiomyocyte cell cycle control and growth estimation in vivo-an analysis based on cardiomyocyte nuclei. Cardiovasc Res. 2010;86:365-73.

13. Quaini F, Cigola E, Lagrasta C, et al. End-stage cardiac failure in humans is coupled with the induction of proliferating cell nuclear antigen and nuclear mitotic division in ventricular myocytes. Circ Res. 1994;75:1050-63.

14. Kajstura J, Zhang X, Reiss K, et al. Myocyte cellular hyperplasia and myocyte cellular hypertrophy contribute to chronic ventricular remodeling in coronary artery narrowing-induced cardiomyopathy in rats. Circ Res. 1994;74:383-400.

15. Soonpaa MH, Field LJ. Survey of studies examining mammalian cardiomyocyte DNA synthesis. Circ Res. 1998;83:15-26.

16. Marino TA, Haldar S, Williamson EC, et al. Proliferating cell nuclear antigen in developing and adult rat cardiac muscle cells. Circ Res. 1991;69:1353-60.

17. Rona G. Catecholamine cardiotoxicity. J Mol Cell Cardiol. 1985;17:291-306.

18. Díaz-Muñoz M, Alvarez-Pérez MA, Yáñez L, et al. Correlation between oxidative stress and alteration of intracellular calcium handling in isoproterenol-induced myocardial infarction. Mol Cell Biochem. 2006;289:125-36.

19. Skalli O, Gabbiani G, Babaï F, et al. Intermediate filament proteins and actin isoforms as markers for soft tissue tumor differentiation and origin. II. Rhabdomyosarcoma. Am J Pathol. 1988;130:515-31.

20. Glotzer $M$. The molecular requirements for cytokinesis. Science. 2005;307:1735-9.

21. Pollard TD. Mechanics of cytokinesis in eukaryotes. Curr Opinion Cell Biol. 2010;22:50-6.

22. Ahuja P, Perriard E, Perriard JC, et al. Sequential myofibrillar breakdown accompanies mitotic division of mammalian cardiomyocytes. J Cell Sci. 2004;117:3295-306.

23. Willis MS, Schisler JC, Portbury AL, et al. Build it up-tear it down: Protein quality control in the cardiac sarcomere. Cardiovasc Res. 2009;81:439-48.

24. Glotzer M. Animal cell cytokinesis. Annu Rev Cell Dev Biol. 2001;17:351-86.

25. Dorée $M$. Le déclenchement de la mitose chez les eucaryotes supérieurs. Med Sci. 2003;19:299-307.

26. Chimenti C, Kajstura J, Torella D, et al. Senescence and death of primitive cells and myocytes lead to premature cardiac aging and heart failure. Circ Res. 2003;93:604-13.

27. Nadal-Ginard B, Kajstura J, Leri A, et al. Myocyte death, growth, and regeneration in cardiac hypertrophy and failure. Circ Res. 2003;92:139-50.

28. Beltrami AP, Barlucchi L, Torella D, et al. Adult cardiac stem cells are multipotent and support myocardial regeneration. Cell. 2003;114:763-76. 